\title{
Recent patent applications in oligonucelotide synthesis
}

\begin{tabular}{|c|c|c|c|c|c|}
\hline Patent number & Description & Assignee & Inventor & $\begin{array}{l}\text { Priority } \\
\text { application } \\
\text { date }\end{array}$ & $\begin{array}{c}\text { Publication } \\
\text { date }\end{array}$ \\
\hline US 8362234 & $\begin{array}{l}\text { New linking compounds useful for solid-phase synthesis } \\
\text { of small-molecule libraries and oligomeric materials, } \\
\text { e.g., nucleotides, peptides and oligosaccharides. }\end{array}$ & $\begin{array}{l}\text { Archemix } \\
\text { (Cambridge, MA, } \\
\text { USA) }\end{array}$ & Hatala PJ, Kurz M & $3 / 24 / 2006$ & $1 / 29 / 3013$ \\
\hline US 20130020194 & $\begin{array}{l}\text { An electrode array comprising electrodes provided on a } \\
\text { substrate and an adsorbed porous reaction layer where } \\
\text { each electrode has a surface; useful for electrochemical } \\
\text { synthesis of oligonucleotides, peptides and other chemi- } \\
\text { cal species. }\end{array}$ & Strathmann MP & Strathmann MP & $9 / 25 / 2012$ & $1 / 24 / 2013$ \\
\hline $\begin{array}{l}\text { WO 2013003597, } \\
\text { US } 20130023035\end{array}$ & $\begin{array}{l}\text { A new recombinant microorganism comprising an } \\
\text { exogenous type II toxin gene encoding a toxin having ribo- } \\
\text { nuclease activity; used for controlled biocontainment and } \\
\text { for the synthesis of lipids and/or hydrocarbons. }\end{array}$ & $\begin{array}{l}\text { ExxonMobil } \\
\text { Research \& } \\
\text { Engineering } \\
\text { (Annandale, NJ, } \\
\text { USA) }\end{array}$ & $\begin{array}{l}\text { Akella S, Bauman N, } \\
\text { Bielinksi VA, Bower S, } \\
\text { Boyd KL, Roessler PG, } \\
\text { Lyons BK }\end{array}$ & 6/30/2011 & $\begin{array}{l}\text { 1/3/2013, } \\
1 / 24 / 2013\end{array}$ \\
\hline $\begin{array}{l}\text { FR 2977811, } \\
\text { WO } 2013007944\end{array}$ & $\begin{array}{l}\text { A material comprising a porous support on which func- } \\
\text { tionalized nanoparticles are grafted by covalent bonds; } \\
\text { useful for growing peptides or oligonucleotides in an } \\
\text { automated synthesizer. }\end{array}$ & $\begin{array}{l}\text { National Centre for } \\
\text { Scientific Research } \\
\text { (Paris), Claude } \\
\text { Bernard University } \\
\text { Lyon } 1 \\
\text { (Lyon, France) }\end{array}$ & $\begin{array}{l}\text { Chaix C, de Crozals G, } \\
\text { Farre C }\end{array}$ & 7/12/2011 & $\begin{array}{l}\text { 1/18/2013 } \\
1 / 17 / 2013\end{array}$ \\
\hline WO 2013006953 & $\begin{array}{l}\text { An isolated or purified nucleic acid molecule comprising } \\
\text { a nucleotide sequence; useful for altering levels of canna- } \\
\text { binoid compounds and synthesizing a naturally occurring } \\
\text { cannabinoid compound in an organism, cell or tissue. }\end{array}$ & $\begin{array}{l}\text { National Research } \\
\text { Council of Canada } \\
\text { (Ottawa, Ontario, } \\
\text { Canada), University } \\
\text { of Saskatchewan } \\
\text { (Saskatoon, } \\
\text { Saskatchewan, } \\
\text { Canada), Page JE, } \\
\text { Stout JM }\end{array}$ & Page JE, Stout JM & 7/13/2011 & $1 / 17 / 2013$ \\
\hline JP 2013009623 & $\begin{array}{l}\text { A method for synthesis of protein using a cell-free system, } \\
\text { involving performing a transfer reaction in vitro as a tem- } \\
\text { plate without making a circular DNA linear, and perform- } \\
\text { ing a translation reaction using, e.g., a complex obtained } \\
\text { after a transfer reaction. }\end{array}$ & $\begin{array}{l}\text { Shimadzu (Kyoto, } \\
\text { Japan), Tohoku } \\
\text { University } \\
\text { (Sendai, Japan) }\end{array}$ & $\begin{array}{l}\text { Ando E, Ezure T, } \\
\text { Sato Y, Uozumi N }\end{array}$ & 6/29/2011 & $1 / 17 / 2013$ \\
\hline WO 2011026140 & $\begin{array}{l}\text { An engineered centromere comprising tandem repeats of } \\
\text { a DNA sequence containing a binding motif for the DNA } \\
\text { binding protein; used, e.g., in a plant artificial chromo- } \\
\text { some for transgenic plants and for the synthesis of large } \\
\text { molecules. }\end{array}$ & $\begin{array}{l}\text { University of } \\
\text { Georgia Research } \\
\text { Foundation (Athens, } \\
\text { GA, USA) }\end{array}$ & Dawe RK, Kelley DR & $8 / 31 / 2009$ & $9 / 28 / 2012$ \\
\hline US 20110256031 & $\begin{array}{l}\text { A system for the automated synthesis of biopolymers and } \\
\text { synthetic polymers; has a transport sub-system returning } \\
\text { reaction-chamber carriers output. }\end{array}$ & $\begin{array}{l}\text { Mulligan J, } \\
\text { Parker H, } \\
\text { Tabone JC, Oligoco } \\
\text { (Bothell, WA, USA) }\end{array}$ & $\begin{array}{l}\text { Mulligan J, Parker H, } \\
\text { Tabone JC }\end{array}$ & 2/22/2010 & 10/0/2011 \\
\hline WO 2007123744 & $\begin{array}{l}\text { A system for sequencing one or more polynucleotides by } \\
\text { synthesis analysis, comprising a solid substrate, a fluid } \\
\text { direction system, a temperature control system, an illu- } \\
\text { mination system, a detector component and a computer } \\
\text { system operably coupled to the detector. }\end{array}$ & $\begin{array}{l}\text { Illumina (San } \\
\text { Diego), Solexa } \\
\text { (Hayward, CA, } \\
\text { USA), Lynx } \\
\text { Therapeutics } \\
\text { (Hayward, CA, USA) }\end{array}$ & $\begin{array}{l}\text { Banerjee S, } \\
\text { Barnes C, } \\
\text { Benson KCL, } \\
\text { Bridgham J, } \\
\text { Bryant J, Buermann D, } \\
\text { Etchin S, Ho J, Lee X, } \\
\text { Lundberg P, } \\
\text { Maisinger K, } \\
\text { Obradovic B, } \\
\text { Pratt M, } \\
\text { Rasolonjatovo I, } \\
\text { Reed M, Rodighiero C, } \\
\text { Sankar S, Schroth G, } \\
\text { Sizto N, Swerdlow H, } \\
\text { Vermaas E }\end{array}$ & $3 / 31 / 2006$ & $11 / 27 / 2008$ \\
\hline
\end{tabular}

Source: Thomson Scientific Search Service. The status of each application is slightly different from country to country. For further details, contact Thomson Reuters (Search Service), 1800 Diagonal Road, Suite 250, Alexandria, Virginia 22314, USA. Tel: 1 (800) 337-9368 (http://thomsonreuters.com/). 